\title{
Effect of LH on the release of cyclic AMP by the rabbit ovary perfused in vivo and in vitro*
}

\author{
G. Selstam, P. O. Janson and S. Eden \\ Department of Physiology and Department of Obstetrics and Gynecology, \\ University of Göteborg, Göteborg, Sweden
}

\begin{abstract}
Summary. After perfusion of 10 rabbit ovaries in vitro with a modified Krebs bicarbonate buffer containing dextran and glucose, the concentration of cAMP in the perfusion medium was significantly increased 2.5 min after stimulation with $10 \mu \mathrm{g}$ $\mathrm{LH} / \mathrm{ml}$ medium and was higher at 15 and $30 \mathrm{~min}$. Intravenous injection of $100 \mu \mathrm{g}$ LH/rabbit caused a significant increase of cAMP concentrations in the ovarian venous blood from 8 ovaries 10 min after the injection and the cAMP concentrations were higher after 15 and $30 \mathrm{~min}$. The ovarian blood flow was not changed after the $\mathrm{LH}$ injection. It is concluded that perfusion techniques can be useful in analysis of the mechanisms and physiological significance of release of cAMP from the ovary after hormonal stimulation.
\end{abstract}

\section{Introduction}

The role of cyclic $3^{\prime}, 5^{\prime}$-adenosine monophosphate (cAMP) as a possible mediator in gonadotrophic stimulation of the ovary was first suggested by Marsh \& Savard $(1964 a, b)$ on the basis of studies with slices of $C L$ to which addition of dibutyryl-cAMP increased ovarian steroidogenesis and glycogenolysis. Since then, LH has been shown to increase the cAMP content in several ovarian preparations (see Selstam et al., 1976), including the rabbit ovary (Dorrington \& Kilpatrick, 1969). The rise in cAMP after LH stimulation is apparently due to stimulation of the adenylate cyclase activity, since LH does not seem to influence ovarian phosphodiesterase activity (Dorrington \& Kilpatrick, 1969; Marsh, 1970; Rosberg, Selstam \& Ahrén, 1974). It has been shown in the rat that LH-stimulated increases in tissue levels of cAMP in prepubertal ovaries, preovulatory follicles and CL are accompanied by a considerable release of the nucleotide into the incubation medium (Ahrén et al., 1974; Selstam et al., 1974; Nilsson, Rosberg \& Ahrén, 1974; Herlitz, Hamberger, Rosberg \& Ahrén, 1974). A similar release from the ovary in vivo has hitherto not been reported for any other species. The aim of the present study was to establish whether LH causes a release of cAMP into the medium in vitro in the rabbit, and whether such a release also occurs under conditions in vivo.

\section{Materials and Methods}

Virgin albino Swedish land rabbits, 4-6 months old and weighing $2 \cdot 5-3 \cdot 5 \mathrm{~kg}$, were used. The animals were allowed free access to a standard laboratory diet (Astra-Ewo pellets) and water.

Bovine LH (NIH-LH-B8) provided by the Endocrinology Study Section of the National Institutes of Health, Bethesda, Maryland, U.S.A., was dissolved in perfusion medium for the in-vitro experiments and in saline for i.v. injection for the in-vivo studies. Sodium pentobarbital (Nembutal: Abbott, Queenborough, England) was administered i.v. at a dose of $30 \mathrm{mg} / \mathrm{kg}$ for the induction of anaesthesia. Heparin (1500 i.u.: Vitrum Ltd, Stockholm, Sweden) was given i.v. immediately after arterial catheterizations. Dextran T70 (mol. wt 70,000) was obtained from Pharmacia Ltd, Uppsala, Sweden. Tritiated cAMP (sp. act. $24 \mathrm{Ci} / \mathrm{mmol}$ ) was purchased from New England Nuclear Co.,

* Reprint requests to Dr G. Selstam, Department of Physiology, Medicinaregatan 11, S-400 33 Göteborg 33, Sweden. 
Boston, Massachusetts, U.S.A. Cyclic 3',5'-AMP-dependent protein kinase and the protein kinase inhibitor was obtained from Sigma Co., St Louis, Missouri, U.S.A.

The equipment for in-vitro perfusion has been described elsewhere (Ahrén, Janson \& Selstam, 1972,1975 ). In anaesthetized rabbits an aortic segment involving the origins of the ovarian arteries was dissected free, and the aorta was tied distal to the ovarian arteries. The aortic segment was cannulated in an anterograde direction and chilled $\left(4^{\circ} \mathrm{C}\right)$, oxygenated $\left(95 \% \mathrm{O}_{2}+5 \% \mathrm{CO}_{2}\right)$ perfusion fluid was infused at a pressure of $50 \mathrm{mmHg}$. The perfusion fluid consisted of $10 \%$ dextran in Krebs bicarbonate buffer, but with half the normal calcium concentration $(1.25 \mathrm{~mm})$, and containing $1 \mathrm{mg}$ glucose $/ \mathrm{ml}$. During continuous perfusion the aortic segment, one ovary and its vascular pedicle was dissected free and lifted out of the abdominal cavity, leaving the transected ovarian vein and utero-ovarian vascular anastomoses open. The contralateral ovarian artery was ligated and cut close to the aorta. The ovarian preparation was transferred to the perfusion apparatus in which the perfusion was continued for $30 \mathrm{~min}$ in a non-recycling system at $38^{\circ} \mathrm{C}$ at $50 \mathrm{mmHg}$ and the fiuid was oxygenated with $95 \% \mathrm{O}_{2}+5 \% \mathrm{CO}_{2}$ ('preperfusion'). During this period of stabilization the flow rate of perfusion fluid through the preparation was measured. The preparation was then transferred to another perfusion apparatus and perfused under the same conditions, the only difference being that the perfusion fluid $(25 \mathrm{ml})$ was recycled through the preparation. After perfusion for 30 min, $0.7 \mathrm{ml}$ fluid was withdrawn from the system for cAMP analysis and $\mathrm{LH}$, dissolved in $0.7 \mathrm{ml}$ perfusion medium, was introduced into the perfusion line to a final concentration of $10 \mu \mathrm{g} / \mathrm{ml}$. The perfusion was then continued and at $2.5,15 \mathrm{~min}$ and after the perfusion $(30 \mathrm{~min}) 0.7 \mathrm{ml}$ samples were withdrawn for analysis of cAMP.

The preparation used for the perfusions in vivo involved serial analyses of venous blood from an ovary in situ receiving blood via an intact arterial circulation (Type I in-vivo perfusion of Ahrén et al., 1972). A detailed description of the experimental procedure has been published by Janson \& Albrecht (1975). The venous outflow from the ovary, fat and connective tissue along the ovarian vascular pedicle was collected at timed intervals (5-10 min). Arterial samples were taken from the left carotid artery. Aliquots from venous and arterial blood were taken for measurement of cAMP levels. Fifteen to $30 \mathrm{~min}$ after the start of blood collection, $100 \mu \mathrm{g} \mathrm{LH}$ dissolved in $1.0 \mathrm{ml}$ saline was given i.v. and blood collection was continued for another $40 \mathrm{~min}$. In control rabbits, $1.0 \mathrm{ml}$ saline was given i.v. instead of $\mathrm{LH}$.

The blood samples were collected in heparinized tubes at $4^{\circ} \mathrm{C}$. After centrifugation at $6000 \mathrm{~g}$ for $4 \mathrm{~min}, 0.5 \mathrm{ml}$ plasma was withdrawn and stored at $-80^{\circ} \mathrm{C}$ until analysis. The plasma samples were thawed and mixed with $2 \mathrm{ml}$ cooled ethanol. After $5 \mathrm{~min}$ the samples were centrifuged at $15,000 \mathrm{~g}$ for $15 \mathrm{~min}$ and two $1.0 \mathrm{ml}$ aliquots of supernatant were evaporated under a stream of air to dryness at room temperature. The residues were dissolved in $0.2 \mathrm{ml} 50 \mathrm{~mm}$-sodium acetate buffer. The cAMP content was determined in these aliquots and the perfusion media by a modification of the procedure of Gilman (1970) as has been described earlier (Selstam et al., 1974). The recovery of the plasma cAMP when 10-100 pmol cAMP was added varied between 84.3 and $100 \cdot 5 \%$. Values in the paper are given as mean \pm S.E.M. The significance of differences was assessed by Student's $t$ test. A $P$ value of 0.05 or less was considered significant.

\section{Results}

After $30 \mathrm{~min}$ perfusion in vitro significant amounts of cAMP were measurable in the perfusion medium $(4.5 \pm 0.6 \mathrm{pmol} / \mathrm{ml}$; number of observations $(n)=10, P<0.01)$. The addition of $10 \mu \mathrm{g} \mathrm{LH}$ after perfusion for $30 \mathrm{~min}$ caused a rapid increase in the levels of cAMP in the medium. By $2.5 \mathrm{~min}$ after addition of LH, cAMP levels had increased from $4.5 \pm 0.6 \mathrm{pmol} / \mathrm{ml}(n=10)$ to $13.3 \pm 4 \cdot 2 \mathrm{pmol} / \mathrm{ml}(n=6$; $P<0 \cdot 05)$. The concentration of cAMP was higher at $15 \mathrm{~min}(27 \cdot 3 \pm 9 \cdot 4 \mathrm{pmol} / \mathrm{ml}, n=3)$ and remained high at $30 \mathrm{~min}$ after the start of hormonal stimulation $(29.3 \pm 5.9 \mathrm{pmol} / \mathrm{ml}, n=4$, compared with $7 \cdot 7 \pm 3 \cdot 0 \mathrm{pmol} / \mathrm{ml}, n=3$, in ovaries not perfused with $\mathrm{LH} ; \boldsymbol{P}<0 \cdot 02)$. The flow of perfusate through the preparation was constant during the whole perfusion period.

The results of the perfusions in vivo are shown in Table 1. In the control rabbits, the concentration of cAMP in the ovarian venous blood did not change during the perfusion, and there was no difference 
Table 1. Effect of $100 \mu \mathrm{g} \mathrm{LH}$ on the release of cAMP (pmol/ml plasma) from the rabbit ovary perfused in vivo (mean \pm S.E.M., $n=$ no. of observations)

\begin{tabular}{|c|c|c|c|}
\hline \multirow[b]{3}{*}{$\begin{array}{l}\text { Perfusion time } \\
\text { (min) }\end{array}$} & \multicolumn{3}{|c|}{ Cyclic AMP levels } \\
\hline & \multirow{2}{*}{$\begin{array}{c}\text { Arterial } \\
\text { blood } \\
(n=6)\end{array}$} & \multicolumn{2}{|c|}{ Ovarian venous blood } \\
\hline & & $\begin{array}{c}-\mathrm{LH} \\
(n=3)\end{array}$ & $\begin{array}{c}+\mathbf{L H} \\
(n=5)\end{array}$ \\
\hline-10 & $63 \pm 14$ & $66 \pm 19$ & $60 \pm 20$ \\
\hline-5 & $57 \pm 12$ & $58 \pm 16$ & $50 \pm 11$ \\
\hline 0 & $57 \pm 10$ & $60 \pm 17$ & $50 \pm 11$ \\
\hline 5 & $64 \pm 11$ & $63 \pm 18$ & $107 \pm 24$ \\
\hline 10 & $65 \pm 12$ & $65 \pm 19$ & $158 \pm 25^{*}$ \\
\hline 15 & $64 \pm 13$ & $65 \pm 17$ & $221 \pm 17^{* *}$ \\
\hline 20 & $60 \pm 12$ & $67 \pm 17$ & $225 \pm 46^{*}$ \\
\hline 30 & $65 \pm 13$ & $71 \pm 18$ & $234 \pm 77$ \\
\hline
\end{tabular}

Significantly different from corresponding control level $(-\mathrm{LH})$ :

${ }^{*} P<0.05 ; * * P<0.01$.

in the concentration of cAMP between ovarian venous and systemic arterial blood. The i.v. injection of $100 \mu \mathrm{g} \mathrm{LH}$ caused a rise in the concentration of cAMP in the ovarian venous blood that was significant after $10 \mathrm{~min}$ and remained elevated from 15 to $30 \mathrm{~min}$. The cAMP concentrations in arterial blood of control and LH-injected rabbits did not differ (not shown in the table). The blood flow through the preparation was not significantly altered by LH; during the first 30 min after LH or saline injections the blood pressure in the femoral artery was stable.

\section{Discussion}

The results clearly demonstrate that cAMP can be released from the perfused rabbit ovary in vitro and in vivo after stimulation by LH. In comparison with incubated rat ovaries the release of cAMP from perfused rabbit ovaries reached a plateau earlier-after approximately 15 min compared with $120 \mathrm{~min}$ in the rat (Selstam et al., 1976). A similar pattern in the release of cAMP reaching maximal levels within 10-20 min after hormonal stimulation has been shown for other perfused organs such as liver in vitro (Exton, Lewis, Ho \& Park, 1972) and adrenals in vivo (Peytremann, Nicholson, Hardman \& Liddle, 1973; Espiner, Livesey, Ross \& Donald, 1974). The difference in the cAMP release pattern between the perfused rabbit ovary and the incubated rat ovary can probably be ascribed to a uniform and rapid distribution of the hormone in the perfused organ and an efficient washout of cAMP from the extracellular space via an intact circulation. The difference in magnitude of cAMP levels in the venous perfusate in vitro and in ovarian venous blood following LH stimulation is probably due to differences in experimental conditions and needs further investigation.

Since LH elicited no measurable change in ovarian blood flow, the increase in ovarian venous concentration was probably due to an increased output of cAMP from the gland. LH has, however, at concentrations similar to those used in the present study, been shown to increase the blood flow in vivo in intact ovaries of rats (Ellis, 1961; Wurtman, 1964) and rabbits (Janson, 1975). The lack of this vascular effect of LH in the present perfusion systems may be due to the hyperaemia consistently seen after handling of the ovary during surgery (Janson \& Selstam, 1975) rendering the ovarian vessels unresponsive to further dilatation by $\mathbf{L H}$.

In the in-vitro perfusion a small but significant release of cAMP was seen in the absence of LH. In the in-vivo perfusion, there were no significant differences in systemic arterial and ovarian venous blood concentrations of cAMP in control rabbits. A small release in vivo would, however, hardly be measurable with the present technique. A release from unstimulated ovaries in vitro is in contrast to observations on incubated rat ovaries, with which such a release has not been found (Selstam et al., 1974). The difference might be due to a number of factors, e.g. a species difference, differences in circulating levels of hormones at the moment of extirpation of the ovary, more efficient washout 
of cAMP via the circulation or a lower activity of the extracellularly active phosphodiesterase enzyme in the perfused rabbit ovary than in the incubated rat ovary (Rosberg, Selstam \& Isaksson, 1975).

Since it has now been shown in various ovarian preparations that gonadotrophic stimulation not only elicits an increase of cAMP in the ovarian tissue, but also a release of the nucleotide of considerable magnitude, this release must be taken into consideration when quantitative aspects of cAMP formation and degradation are studied. An advantage in using a perfusion system for measuring cAMP release is that the dynamics of a stimulatory process can be monitored and the physiological significance of the release analysed.

This research was supported by grants from the Swedish Medical Research Council (B74-03X-27), the Faculty of Medicine, University of Göteborg, Magnus Bergvall's Foundation and Göteborgs Läkaresällskap. We thank the National Institutes of Health, U.S.A., for the gift of LH. Valuable advice was given by Professor Kurt Ahrén, and skilful technical assistance by Miss Stina Öberg and Miss Barbro Henskog.

\section{References}

Ahrén, K., Janson, P.O. \& Selstam, G. (1972) Perfusion of ovaries in vitro and in vivo. Acta endocr., Copenh., Suppl. 158, 285-305.

Ahrén, K., Herltuz, H., Nilsson, L., Perklev, T., RosberG, S. \& Selstam, G. (1974) Gonadotropins and cyclic AMP in various compartments of the rat ovary. In Gonadotropins and Gonadal Function, pp. 364-375. Ed. N. R. Moudgal. Academic Press, New York.

Ahrén, K., Janson, P.O. \& Selstam, G. (1975) A technique for perfusion of rabbit ovaries in vitro. In Methods in Enzymology, Vol. 39, Part D, pp. 230-237. Eds J. G. Hardman \& B. W. O'Malley. Academic Press, New York.

DORRINGTON, J.H. \& Kilpatrick, R. (1969) The synthesis of progestational steroids by the rabbit ovary. In The Gonads, pp. 27-49. Ed. K. W. McKerns. Appleton-Century-Crofts, New York.

Ellıs, S. (1961) Bioassay of luteinizing hormone. Endocrinology 68, 334-340.

EsPiner, E.A., Livesey, J.H., Ross, J. \& DONALD, R.A. (1974) Dynamics of cyclic adenosine $3^{\prime}, 5^{\prime}$-monophosphate release during adrenocortical stimulation in vivo. Endocrinology 95, 838-846.

ExtoN, J.H., LEWIs, S.B., Ho, R.J. \& PARK, C.R. (1972) The role of cyclic AMP in the control of hepatic glucose production by glucagon and insulin. $A d v$. cyclic Nucl. Res. 1, 91-101.

Gilman, A.G. (1970) A protein binding assay for adenosine 3',5'-cyclic monophosphate. Proc. natn. Acad. Sci. U.S.A. 67, 305-312.

Herlitz, H., Hamberger, L., Rosberg, S. \& Ahrén, K. (1974) Cyclic AMP in isolated corpora lutea of the rat: influence of gonadotrophins and prostaglandins. Acta endocr., Copenh. 77, 737-752.

JANSON, P.O. (1975) Effects of the luteinizing hormone on blood flow in the follicular rabbit ovary, as measured by radioactive microspheres. Acta endocr., Copenh. 79, 122-133.

JANSON, P.O., \& AlBrecht, I. (1975) Methodological aspects of blood flow measurement in ovaries containing corpora lutea.J. appl. Physiol. 38, 288-293.

Janson, P.O. \& Selstam, G. (1975) A comparison between direct and indirect measurements of blood flow in the follicular ovary of the rabbit. Acta physiol. scand. 94, 1-7.

Marsh, J.M. (1970) The stimulatory effect of luteinizing hormone on adenyl cyclase in the bovine corpus luteum. J. biol. Chem. 245, 1596-1603.

MARSH, J.M. \& SAVARD, K. (1964a) The effect of 3',5'AMP on progesterone synthesis in the corpus luteum. Fedn Proc. Fedn Am. Socs exp. Biol. 23, 462.

MARSH, J.M. \& SAVARD, K. (1964b) The activation of luteal phosphorylase by luteinizing hormone. J. biol. Chem. 239, 1-7.

Nilsson, L., Rosberg, S. \& AHrén, K. (1974) Characteristics of the cyclic $3^{\prime}, 5^{\prime}$-AMP formation in isolated ovarian follicles from PMSG-treated immature rats after stimulation in vitro with gonadotrophins and prostaglandins. Acta endocr., Copenh. 77, 559-574.

Peytremann, A., Nicholson, W.E., Hardman, J.G. \& LidDle, G.W. (1973) Effect of adrenocorticotropic hormone on extracellular adenosine 3',5'-monophosphate in the hypophysectomized rat. Endocrinology 92, 1502-1506.

Rosberg, S., Selstam, G. \& Ahrén, K. (1974) Release and degradation of adenosine $3^{\prime}, 5^{\prime}$-monophosphate by the rat ovary. Acta physiol. scand. 91, 30A-31A.

Rosberg, S., Selstam, G. \& Isaksson, O. (1975) Characterization of the metabolism of exogenous cyclic AMP by perfused rat heart and incubated prepubertal rat ovary. Acta physiol. scand. 94, 522-. 535.

Selstam, G., Liljexvist, J., Rosberg, S., Grönquist, L., Perklev, T. \& Ahrén, K. (1974) Comparison between the effect of luteinizing hormone and prostaglandin $\mathrm{E}_{1}$ on ovarian cyclic AMP. Prostaglandins 6, 303-311.

Selstam, G., Rosberg, S., LilJekvist, J., GrönQuist, L., Perklev, T. \& AhrÉN, K. (1976) Differences in action of $\mathrm{LH}$ and FSH on the formation of cyclic AMP in the prepubertal rat ovary. Acta endocr., Copenh. 81 (in press).

WURTMAN, R.J. (1964) An effect of luteinizing hormone on the fractional perfusion of the rat ovary. Endocrinology 75, 927-933. 